\title{
A Systemic Approach to Understand the Conservation Status and Viability of the Critically Endangered Cat Ba Langur
}

\author{
Thuc D. Phan ${ }^{* 1}$, Nam C. Nguyen ${ }^{2,3}$, Ockie J. H. Bosch ${ }^{2,4}$, Thanh V. Nguyen ${ }^{5}$, Tuyen T. Le ${ }^{6}$, \\ Ha T. Tran ${ }^{7,8}$ \\ ${ }^{1}$ Griffith School of Environment, Griffith University, Nathan, Queensland, Australia \\ ${ }^{2}$ Systems Design and Complexity Management, University of Adelaide Business School, Australia \\ ${ }^{3}$ Malik Management Institute, St Gallen, Switzerland \\ ${ }^{4}$ Systemic Excellence Group, Berlin, Germany \\ ${ }^{5}$ Office of the Central Committee, 1A Hung Vuong, Ba Dinh, Ha Noi, Vietnam \\ ${ }^{6}$ Cat Ba Biosphere Reserve Office, 5 Chieu Hoa, Kien An, Hai Phong, Vietnam \\ ${ }^{7}$ VNU Institute of Vietnamese Studies and Development Science, Hanoi, Vietnam \\ ${ }^{8}$ Visiting scholar, the University of Queensland, Queensland, Australia
}

\begin{abstract}
Wildlife conservation is a dynamically complex system, linking seemingly disparate biological and cultural components. This article offers policy professionals an illustration of how a dynamically complex system was diagnosed by applying the system dynamics approach. An integrated method was applied to develop a causal loop diagram, showing the interconnected variables within the system, relating to the conservation status and viability of Cat Ba Langur. Rural poverty, low livelihoods options, human population growth, inappropriate tourism planning, and weak management capacity are challenges that have prevented the langur population from increasing over the last decades. Tragedy of commons and shifting the burden systems archetypes were identified and then leverage points for saving the species were proposed. A shift towards the systems perspective of viewing wildlife conservation as the dynamically complex system enables decision-makers to avoid the unintended consequences emerging from the linear thinking, and find sustainable solutions for both wildlife and human.
\end{abstract}

Keywords: Cat Ba Island; conservation intervention; system dynamics; a dynamically complex system; wildlife conservation 


\section{INTRODUCTION}

To understand the forces affecting wildlife conservation, conservationists have recognized the usefulness of thinking about wildlife conservation as a dynamically complex system. Carter et al., (2014) stated that wildlife conservation requires understanding dynamic interactions between natural and human components, especially the spatial, temporal and organizational interactions between people and wildlife. These are critical for initiating policies and interventions that improve human wellbeing while sustaining wildlife populations and their habitats. Sterling et al., (2010) determined that implementing biodiversity conservation strategies with a focus on individual species, without understanding the wildlife conservation as a dynamically complex system, especially the interactions and feedback loops between species and people can have unintended consequences. It is also necessary to analyze the patterns, causes and consequences of changes in wildlife population and their habitats, human population and land use (Rindfuss et al., 2008), and their dynamic interactions within the system (Bearer et al., 2008).

The dynamic processes between natural and human elements are two main interconnected subsystems within the wildlife conservation system. The natural subsystem includes species population, spatial distribution and their habitats, and the human subsystem comprises socioeconomic, political, demographic, and cultural settings (Carter et al., 2014). More specifically, the local people characteristics and resources management organizations affect wildlife and their habitats in numerous complex ways, such as encroachment on natural forestlands for socio-economic development (Hoekstra et al., 2005), and conservation policies for wildlife. Human impacts on wildlife and their habitats are in turn modifying the functions of ecosystem services that they provide to local residents and organizations in both sites of supply and demand, including access to forest products and cultural values (Manfredo et al., 2009; Carter et al., 2014).

These perspectives on the wildlife conservation highlight that wildlife conservation is a dynamically complex system with significant feedbacks of interconnected elements between species and human. It is necessary, therefore, to systemically understand how these elements link together, and to characterize their dynamic interactions that take into account both positive and negative feedback loops within the system. This is the domain of system 
dynamics, which is used to understand the feedback mechanism within systems that influence their behavior over time (Kelly et al., 2013).

System dynamics approach has been applied in many fields, for example, health (Cavana et al., 1999), business (Sterman, 2000), human resource management (Quatro et al., 2007), and environmental conflict management (Elias, 2008). However, the application of system dynamics in wildlife conservation has not been attempted, especially the conservation status and viability of the Critically Endangered Cat Ba Langur.

The Cat Ba Langur, Trachypithecus poliocephalus (Trouessart, 1911) is an endemic species of Cat $\mathrm{Ba}$ Island, Vietnam. This species is probably the most endangered species of the World's colobines and is assessed as Critically Endangered Species (Bleisch et al., 2008). Cat Ba Langur is also listed under the world's 25 most endangered primates from 2000 to 2014 (Passaro et al., 2014). Although many efforts have been attempted to conserve the langurs and their habitats, the conservation of this species continues to face major challenges in the population development. More specifically, which drivers have prevented the species population from increasing over last decades? The conservation of the species requires an understanding the dynamic interactions of interconnected elements, relating to the conservation status and viability of the wildlife.

This study aims to systemically understand the conservation status and viability of the Critically Endangered Cat Ba Langur in the Cat Ba Island. More specifically, this study applied a system dynamics approach, coupled with engaging systems perspectives from stakeholders to comprehensively understand the interactions among human population growth, local livelihoods, rural poverty, tourism development and local authority's management capacity on the conservation status and viability of the species through developing a causal loop diagram. Subsequently, systems archetypes and leverage points were identified and analyzed to propose conservation strategies to save the Critically Endangered Cat Ba Langur from extinction.

\section{RESEARCH METHODOLOGY}

System dynamics approach 
A system dynamics approach has been proven to be a powerful tool to understand the complexity and change of any system (Maani and Cavana, 2007), such as the dynamic conservation status of endangered species. The approach offers the paradigm, language and methodology for understanding and dealing with dynamic complexity of reality (Bosch et al., 2007). Multi-dimensional and multi-level stakeholders and relationships between the dependent components of the system are the principles, applied to find the root causes of problems rather than only identifying symptoms (Senge, 2006). As a result, these tools can enable decision-makers to deeply understand the interactions of variables in the system, and provide further insights into systems behaviors which are necessary to create lasting interventions for prolonged problems (Maani and Cavana, 2007).

Causal loop diagrams (CLDs) and systems archetypes are powerful tools and techniques of system dynamics (Maani and Cavana, 2007). The CLDs describe the influences of variables in systems. A positive (s) or negative (o) sign shows whether the variables move in the same or opposite direction (Sterman, 2000). The feedback loops may occur either in a reinforcing (R) or balancing (B) loop type. Reinforcing loops represent growing or declining actions in the systems, whereas balancing are self-correcting mechanisms that counteract and oppose change (Sterman, 2000; Maani and Cavana, 2007).

Systems archetypes are generic systems structures describing the common dynamic processes that characterize the behaviour of the system (Sterman, 2000; Maani and Cavana, 2007). Thus, analysing systems archetypes can often assist in identifying system leverage points in the systems (Senge, 2006). The leverage points where an intervention should have the most influence on the system behaviour (Maani and Cavana, 2007). Each archetype has its leverage point where an intervention strategy could be proposed to improve the situation of systems.

\section{Methods}

A number of methods including literature reviews, interviews, field surveys and focus group discussion was undertaken to identify the problematic situation in conservation status and viability of the species in Cat Ba Island (Figure 1). 


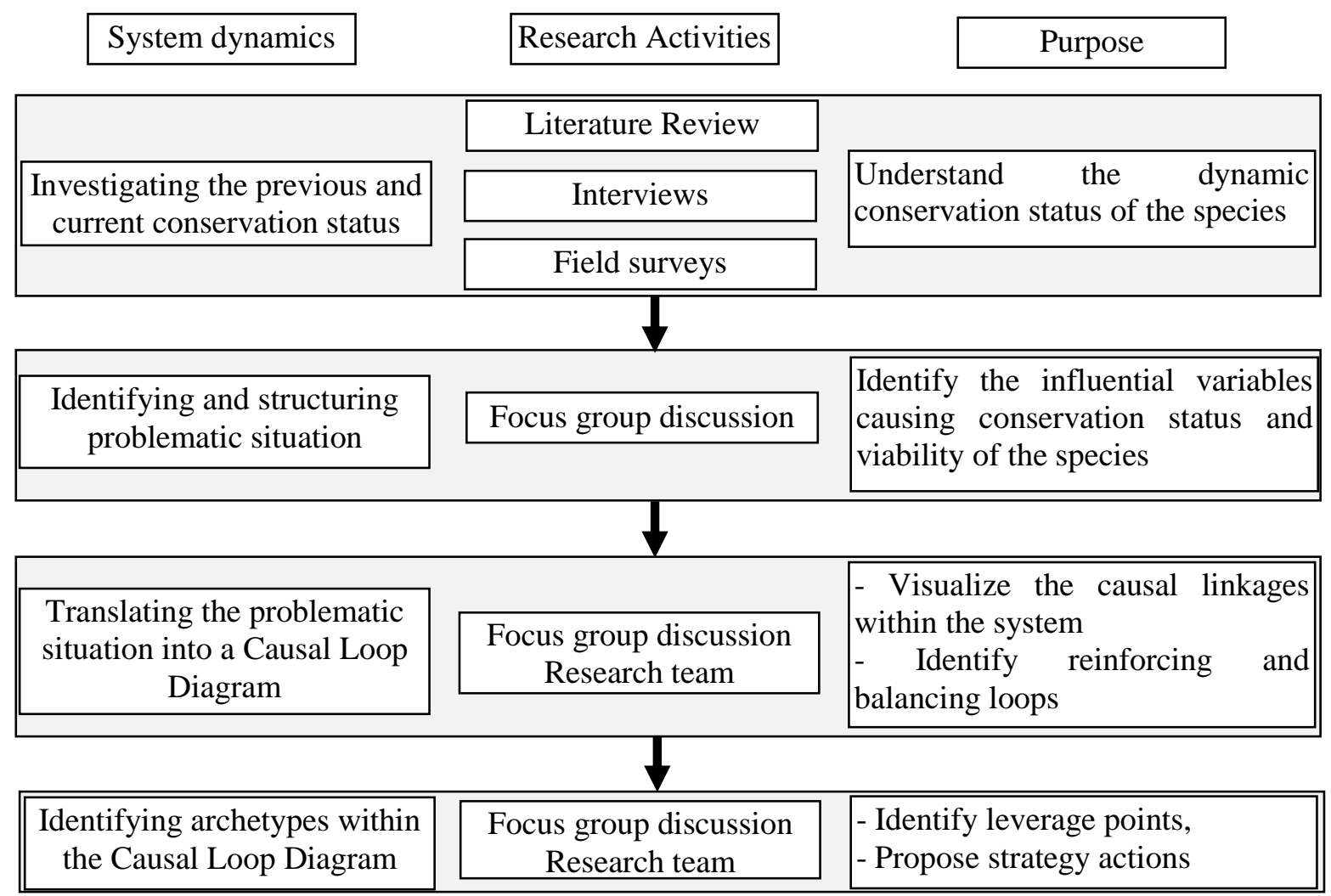

Figure 1: Methodological steps of the study

A literature review was conducted to gather conservation status and life history on previous records of the langurs from reports and other publications dating from 1997 onwards. In addition, a total of 21 members of forest protection groups and 20 rangers and staff of Cat Ba National Park who work where langurs occur, were interviewed to gain insights into the distribution status of the langurs.

A total of 14 localities, eight localities where the presence of the langurs were confirmed by Stenke (2001) and six localities suggested by the interviewees, were crosschecked during field surveys between 2012 and 2013 to confirm whether the langurs were present or absent. Whenever possible, special efforts were also made to count all individuals and identify social structure for each group and sub-population.

Field crews of 4 people surveyed the areas where the presences of the langurs, especially their sleeping sites are believed to be. The surveys were conducted in the early morning (4.30am to $9.30 \mathrm{am})$ and in the late afternoon $(15.00 \mathrm{pm}$ to $19.00 \mathrm{pm})$ when the langurs were moving in and out of the caves, enhancing the ability to count and identify exactly the number of individuals and social structure. 
The results of literature reviews, interviews and field surveys on conservation status of the species were used to develop the conceptual model of the problematic situation in conservation status and viability of the species. A focus group with eight key persons who have extensive knowledge on historical conservation status of the langurs and socioeconomic development in Cat Ba Island was formed to identify variables that seemed to contribute to the problematic situation in conservation status and viability of the langurs.

Subsequently, VensimPLE® (Ventana Systems, Inc.) software version 6.2 was used to translate the problematic situation in conservation status of the species into the CLD which describes the sets of chains of causality which existed in the system (Senge, 2006). The CLD and system archetypes were further developed by the research team, and then refined and discussed with these eight key persons to propose strategy actions to conserve this critically endangered species from extinction.

\section{RESULTS}

\section{Conservation status of the langurs}

The population of Cat Ba Langur was drastically reduced between late 1990s to early 2000s, with population size decreased almost 50\% within 5 years from 1997 to 2001 (Nguyen Phien Ngung, 1997; Nadler and Ha Thang Long, 2000; Stenke, 2001). A hundred langurs on the island were initially confirmed in 1997 (Nguyen Phien Ngung, 1997). However, Nadler and Ha Thang Long (2000) conducted a first exact census of the population and confirmed that about 104-135 langurs existed on the island in 2000. Extremely high hunting pressure caused a dramatic decline during and after the survey (Nadler et al., 2003) and thus an extensive survey found the population to be only 52-54 individuals in 2001 (Stenke, 2001). The population was isolated into seven sub-populations, of which three or four sub-populations were possibly all female groups.

A monitoring program of the langur population from 2001 to 2004, established by the Langur Conservation Project, stated that two groups (7-9 individuals) in Ang Ke, and Ang De-Hien Hao which were listed as unconfirmed status in 2001 were not recorded any more, and only one group of six individuals in Hang Cai, which were listed as two groups in 2001, was recorded in the monitoring program (Stenke and Chu Xuan Canh, 2004). 
The results from interviews and field surveys confirmed that 12 groups of the langurs consisting of a total of about 55 individuals (Table 1) survived until 2013 in Cat Ba Island with an average group size of 4-5 individuals.

Table 1: Current conservation status of the langur on Cat Ba Island

\begin{tabular}{|c|c|c|c|c|}
\hline No & Area & $\begin{array}{l}\text { Group } \\
\text { size }\end{array}$ & $\begin{array}{c}\text { Reproduction } \\
\text { between } 2010 \text { \& } \\
2013 \\
\end{array}$ & Remarks \\
\hline 1 & Gio Cung 1 & 14 & Yes & $\begin{array}{l}\text { Biggest reproductive group on the island; } \\
\text { Contact with Gio Cung 2, 3, 4, Van Ta }\end{array}$ \\
\hline 2 & Gio Cung 2 & 5 & Yes & Contact with Gio Cung 1, 3, 4, Van Ta \\
\hline 3 & Gio Cung 3 & 2 & No & Contact with Gio Cung 1, 2, 4, Van Ta \\
\hline 4 & Gio Cung 4 & 2 & No & Contact with Gio Cung 1, 2, 3, Van Ta \\
\hline 5 & Van Ta & 2 & No & $\begin{array}{c}\text { Contact with Gio Cung 1, 2, 3, and } 4 \\
\text { group }\end{array}$ \\
\hline 6 & Cong Ke 1 & 10 & Yes & $\begin{array}{l}\text { Reproductive group, contact with Cong } \\
\text { Ke 2, Tung Choi and Ang Vem group }\end{array}$ \\
\hline 7 & Cong Ke 2 & 7 & Yes & $\begin{array}{l}\text { Reproductive group, contact with Cong } \\
\text { Ke 1, Tung Choi and Ang Vem group }\end{array}$ \\
\hline 8 & Tung Chuoi & 3 & No & $\begin{array}{l}\text { Contact with Cong Ke 1, } 2 \text { and Ang Vem } \\
\text { group }\end{array}$ \\
\hline 9 & Ang Vem & 2 & No & $\begin{array}{c}\text { Contact with Cong Ke 1, } 2 \text { and Tung } \\
\text { Chuoi group }\end{array}$ \\
\hline 10 & Hang Cai & 5 & No & $\begin{array}{l}\text { Five female group, contact with Hang De } \\
\text { group probable }\end{array}$ \\
\hline 11 & Ang De & 1 & No & $\begin{array}{l}\text { One male group, contact with Hang Cai } \\
\text { group probable }\end{array}$ \\
\hline 12 & Cai Lan $\mathrm{Ha}$ & 2 & No & $\begin{array}{c}\text { Two isolated female group in a peninsula, } \\
\text { contact with other groups and emigration } \\
\text { impossible }\end{array}$ \\
\hline & Total & 55 & & \\
\hline
\end{tabular}

Notes: These following locations are equivalent by Stenke (2001). Gio Cung 1, 2, 3 and Van ta are equivalent to locations of Peninsula location 1, 2 and 3; Cong Ke, Hang Vem, and Tung Chuoi area are equivalent to Cong Ke 1 and Cong Ke 2.

The largest productive sub-population was confirmed to exist in Gio Cung, Van Ta and Tra Bau area, where the highest numbers of the langurs and reproductive units were recorded on the island. Stenke (2001) confirmed that there were three groups with 20 individuals in 2001. The field surveys observed five groups with 25 individuals, which included two females located by Cat Ba Langur Conservation Project from Dong Cong area in 2012. Monitoring records of Gio Cung ranger station confirmed that there were about 24 new 
births from 2003 to 2013, of which three infants had disappeared by January 2010. This sub-population increased by 5 individuals from 2001 to 2013.

The second largest productive sub-population was confirmed to survive in Cong Ke, Hang Vem, and Tung Chuoi area. Stenke (2001) confirmed two groups with 8 individuals in 2001, and Schneider et al., (2010) identified two groups with 16 individuals in 2010. The field surveys observed four groups with 22 individuals. The first group of ten individuals was observed in Cong Ke 1 with four new births in 2013. The second group of seven individuals was confirmed in Cong Ke 2 with two new births in 2013. The third group of three individuals was observed in Ang Vem area, and the last group of two individuals in Tung Chuoi area. This sub-population have about 14 individuals born from 2001 to 2013 (CBLCP, 2013), and increased by about 14 individuals from 2001 to 2013.

Three unproductive and isolated sub-populations with five female individuals, two female individuals, and one male individual are now isolated in Hang Cai area, Cai Lan Ha area and Gia Luan area respectively, confirmed by interviews and field surveys.

Over the past twelve years, the langur population has annually stagnated at 2-5 individuals, leading to very low young generations in the langur population (25\% in 1997; $15 \%$ in 2003 ; 28\% in 2013). Thirty-five infants were probably born and alive between 2001 and 2013. These individuals will be reproductive units for langur population in the coming years, replacing sterile individuals in the population.

One out of 11 individuals in Cai So, Ang Ke and Ang De - Hien Hao areas, mentioned by Stenke in 2001 was confirmed in this study. In addition, two out of four individuals in Dong Cong area which were confirmed by Stenke (2001) are alive and relocated to Gio Cung area in 2012. Evidently, 12 individuals from these areas were lost from the population. However, there are only two productive sub-populations of the langurs on the island and they have increased about 19 individuals since 2001. In addition, seven isolated females from Hang Cai area and Cai Lan Ha area will probably disappear on the island in the next 5 to 10 years. Consequently, the population of the Cat Ba langurs on the island has increased slightly since 2001 and is expected to slightly increase in the next 10 years. Thus, this species will continue to be listed as critically endangered species in the next 10 years because of low population numbers with less than 100 individuals. 


\section{Causal Loop Diagram}

An initial causal loop diagram (CLD) was developed based on the mental models of the participants involved in this study. The final CLD was then further developed by the research team, using information from literature reviews, interviews and field surveys. Local contexts of influencing factors that caused the current conservation status of the species were identified and then grouped into four different themes: species population; rural poverty, livelihoods options and human population growth; tourism development, and local authority's management capacity, which resulted in a total of 7 balancing and 14 reinforcing loops (Figure 2). Details of the interactions of these factors on the species conservation status are highlighted in the Systems Archetypes section.

The four themes in the CLD are differently distinguished by four different color zones. The red zone shows the current conservation status of the species. Poaching and habitat change led to isolated subpopulations and low numbers. The remaining langur population is now divided into five isolated sub-populations, probably only two of which are reproductive, while the others are all-female or male groups and thus non-reproducing social units.

The brown zone illustrates the relationships among human population growth, rural poverty, livelihood options and species conservation status. It can be seen that human population growth, rural poverty and low livelihood options would affect the conservation status of the species through poaching and habitat change. Demand for agricultural land, fuel wood and timbers, and traditional medicine driven by human population growth, directly drive habitat change and species decline. Lack of livelihood options, coupled with low awareness of poor people in remote areas would lead to poaching the wildlife, including Cat $\mathrm{Ba}$ Langur.

The blue zone represents the relationships between tourism development and species population. It seems clear that tourism development without the appropriate planning and management would have effects on the species population through habitat change, bush meat demand and noise pollution. 


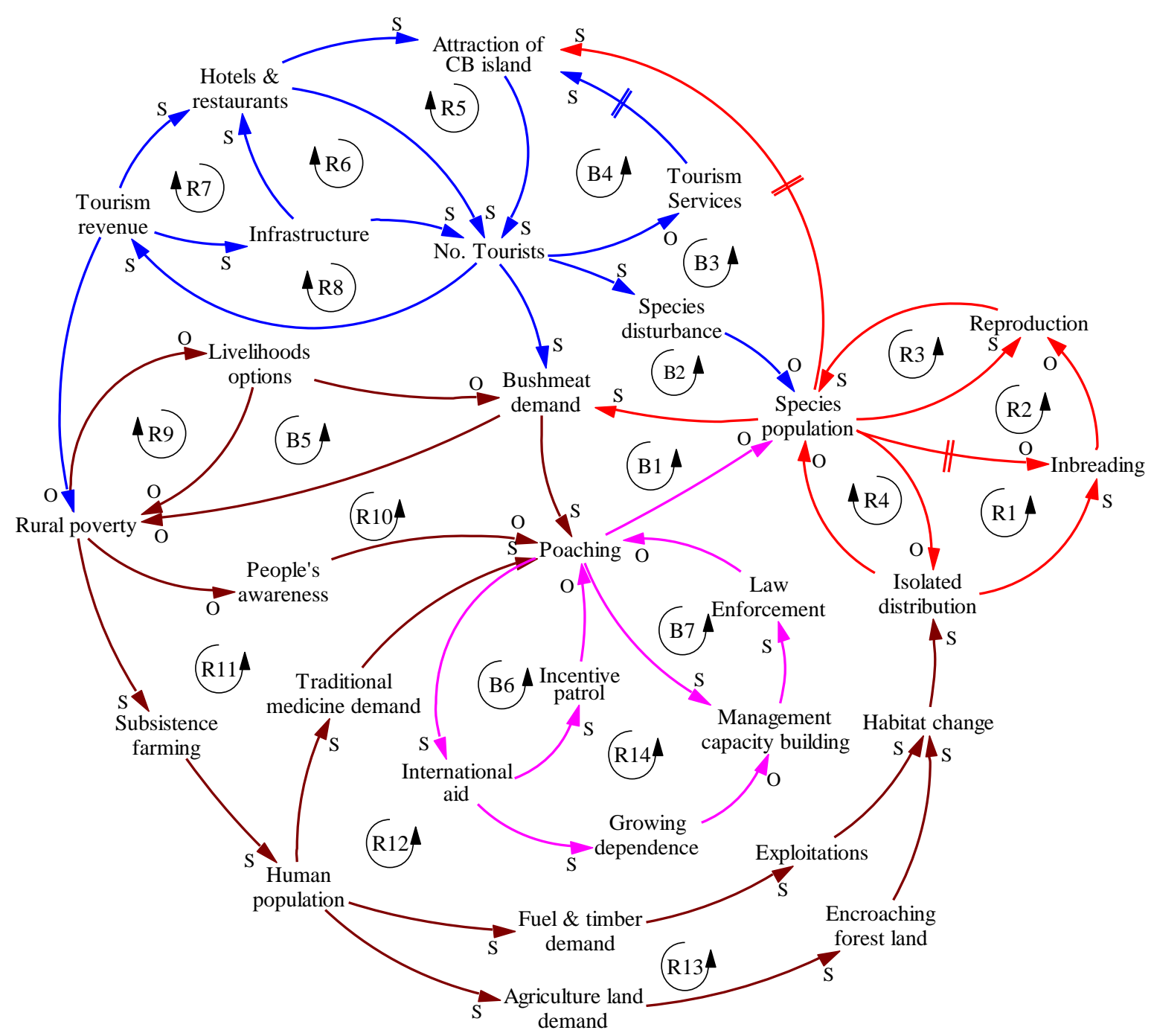

Figure 2: A CLD of conservation status of the langurs

Legend: S (same direction), O (opposite direction), R (reinforcing), B (balancing), red arrows (conservation status), blue arrows (tourism management), brow arrows (human population, livelihoods and rural poverty), pink arrows (management capacity)

The pink zone shows the relationships between local authority's management capacity and species population. It can be seen that the problem of poaching wildlife, including the langur population have attracted financial assistance from international organizations, for example, Cat Ba Langur Conservation Project to conserve the endemic value for the world. This results in growing dependence of local authorities on the international aid, and then weakening management capacity of local authorities, leading to poaching the wildlife.

\section{Systems archetypes}


Analyzing systems archetypes can assist in the identification of system leverage points (Senge, 2006) as a reference to generate strategies to improve the system. In this section, two systems archetypes, which capture the key behaviors and dynamics of the system are discussed; they are 'tragedy of the commons' (appears two times in the CLDs) and 'shifting the burden'.

\section{Tragedy of the commons systems archetypes}

The tragedy of the commons systems archetypes reveals that common sense behavior can lead to destructive consequences over time (Maani and Cavana, 2007). This systems archetype is commonly seen in the use and management of natural resources and public goods where everyone wants to maximize benefits from common resources but the resources are limited. Eventually, the resources are either significantly depleted, eroded, or entirely consumed (Senge, 2006). This common sense is closely related to the forest resources and langur population in Cat Ba Island, clearly illustrated in Figure 3 and 4.

The first tragedy of commons archetype is composed of two balancing loops and five reinforcing loops. These loops cover the main interrelation among rural poverty, human population growth, livelihood options and species population where the local poor wants to satisfy their own demands by exploiting the park's resources causing the habitat changes and species population decrease (Figure 3).

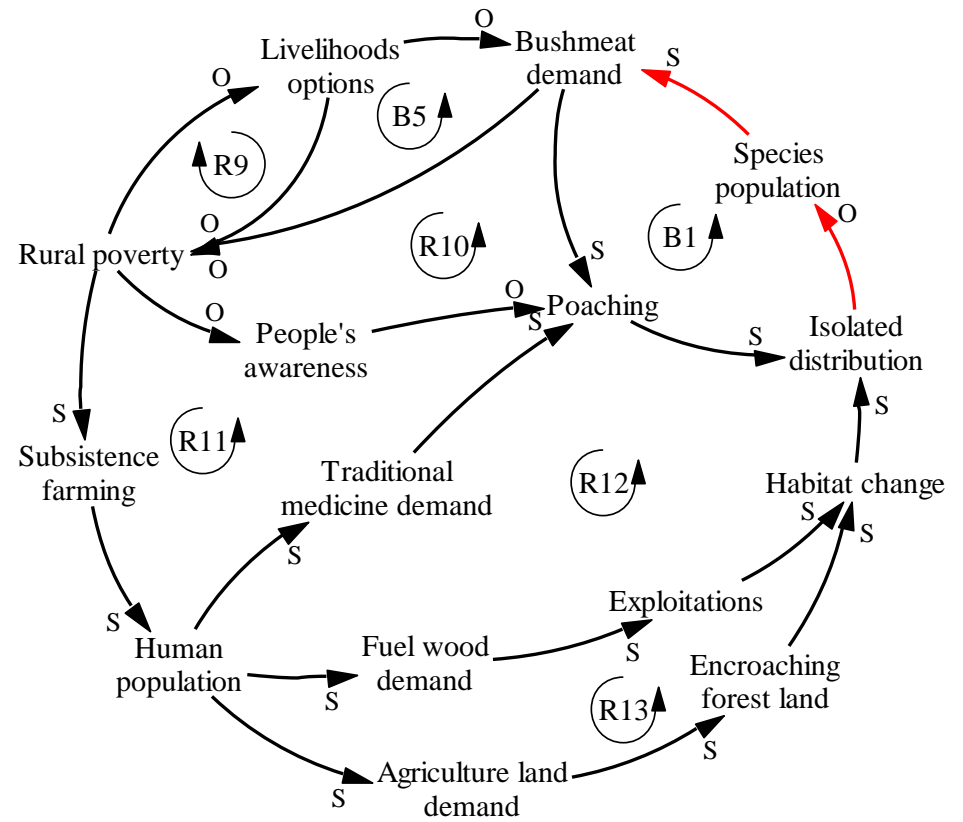

Figure 3: Forest habitats and species population as a 'Tragedy of the commons' systems archetype.

Legend: $\mathrm{S}$ (same direction), O (opposite direction), R (reinforcing), B (balancing), red arrows (conservation status), brow arrows (human population, livelihoods and rural poverty)

Rural poverty and human population growth are one of the reasons leading to encroaching on forestlands as well as hunting for bush meat. Rural poverty and a lack of income 
opportunities for the local residents in remote communes are probably the root causes of the decline in the mammal population in the island. Most of Cat Ba's population lives in rural areas engaging in agriculture, and most of them live in poverty. As local people are poor, and do not have alternatives for their income generation, they will take whatever option is available to increase their incomes, even if it means illegally over exploiting the park's resources (Phan et al., 2014).

In addition, local residents have traditionally accessed to and utilized natural resources in what is now the national park. This access has only been denied due to the designation of Cat Ba National Park in 1986. The formation of the protected area has created negative impacts for the local people, who are isolated from the mainland and lack opportunities for alternative employment and sources of resources. Consequently, local people defy the law and the forest resources are depleted. Potential poachers understand that the hunting of wildlife animals is illegal, but they are induced to do so because of insufficient alternative income (Phan et al., 2014).

Human population is significantly increasing in the island, especially in the rural communes. As a result, the basic demand for agricultural land, fuel wood and traditional medicine increase which have led to illegal land clearing and fragmentation of the island's natural areas, including encroachment into the park (Brooks, 2006).

In this systems structure, the leverage point stays at the reinforcing loop (R9), which indicates that improving livelihoods for local people is necessary to achieve both goals of the sustainability of forest resources and langur population, as well as of local people.

The second tragedy of the commons archetype is composed of three balancing loops and four reinforcing loops, which reveals the relationships between tourism and the species population (Figure 4). The tragedy of the commons occurs when tourism sectors all tried to maximize their tourism revenue by attracting more tourists, result in habitat change and species population decline.

Cat $\mathrm{Ba}$ Island is a famous destination for national and international tourists. Many hotels and restaurants, and tourism services therefore were built to meet the demands of tourists. Consequently, habitat change would occur due to infrastructure development, especially on the forest edges and along the coast lines. In addition, the species population would be 
declined by increasing bush meat demand from tourists. Negative effects from tourists' noise pollution could lead to the disturbance for the species.

In this systems archetype, the leverage points lie in the reinforcing loop (R7), which indicates that it is crucial to develop an integrated master plan for tourism development in the whole island. More specifically, in the master plan,

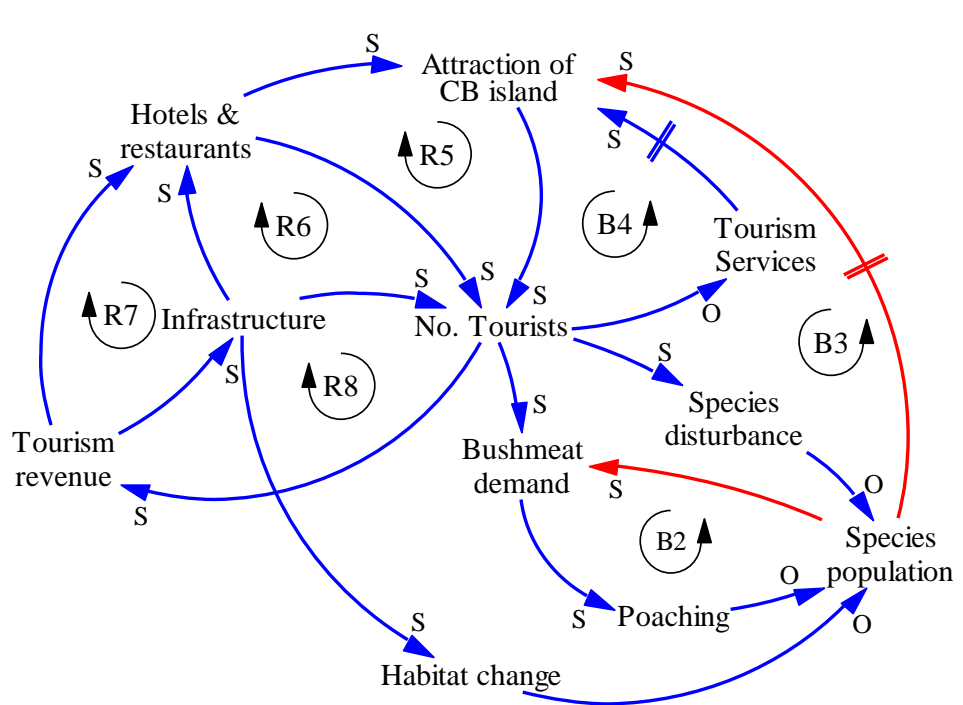

Figure 4: Forest habitats and species population as a

'Tragedy of the commons' systems archetype Legend: $\mathrm{S}$ (same direction), $\mathrm{O}$ (opposite direction), $\mathrm{R}$ (reinforcing), $\mathrm{B}$ (balancing), red arrows (conservation status), blue arrows (tourism development)

following functional zones (core zone, buffer zone and transition zone) of Cat Ba Biosphere Reserve for tourism activities in the island would be necessary. For example, in the core zone, the tourism activities must be prevented, especially in the sensitive areas of the langur's presence. Tourism activities should be allowed in the buffer zone but should have a clear environmental standard for operation and implementation. Massive tourism is allowed to operate in the transition zone. In addition, local authority should have a regulation for tourism companies that the contents of tourism projects must be developed in close cooperation with villagers and local authorities. Especially, priority should be given to local people to work in these projects for their livelihoods.

\section{Shift the burden archetype}

This archetype which consists of two balancing loops and one reinforcing loop represents the dependence of local authorities on international aid for biodiversity conservation, especially the conservation of the langur (Figure 5). Both goal seeking loops (B6 \& B7) are trying to eliminate the poaching of wildlife in the island. The loop B6 shows the symptomatic intervention as an easy solution. Unfortunately, the easy fix has only shortterm benefits but results in altering the symptoms and can leave the real problem untouched or worse (Maani and Cavana, 2007). In addition, the easy fix has side effects that 
exacerbate the real problem (Senge, 2006). In this situation, the ranger forces are encouraged to patrol the forests by an incentive program of Cat $\mathrm{Ba}$ Langur Project. However, the dependence of local authorities on international assistance has been increasing, especially law enforcement forces in the national park. The numbers of patrols of law enforcement's staff reduces when the incentive programs finish. Consequently, illegal activities in the park were happening. The loop B7,

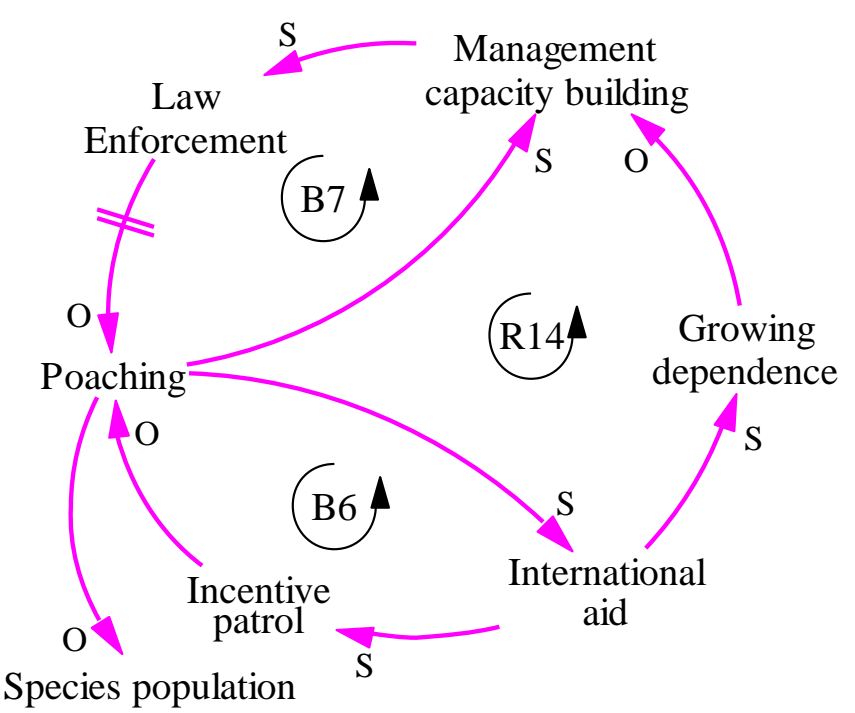

Figure 5: International aid as a 'Shifting the burden' systems archetype

Legend: $\mathrm{S}$ (same direction), $\mathrm{O}$ (opposite direction), $\mathrm{R}$ (reinforcing), B (balancing), pink arrows (management capacity) which has a delay, represents a more fundamental response to the problem. Although the effects of the latter normally will take longer to become evident, the fundamental solution will have a far more effective outcome (Senge, 2006).

The high number of illegal activities within the park, especially the dramatic decline of the langur population is associated with the weak capacity of the local authorities in the island (Brooks, 2006). As a result, the conservation activities in the island have attracted much financial assistance from international organizations over last decades (Dawkins, 2007). For example, Cat Ba Langur Conservation Project was initiated in 2000 to conserve the last remaining individuals of the species in the island. The project has developed an incentive patrol program for the law enforcement forces to control the poaching wildlife in the island. This has helped to temporarily solve the poaching situation in the island as demonstrated in the balancing loop B6. However, after ten years' implementation of the program, many problems still exist in the island because the core issues have not been addressed. In addition, receiving high amounts of international aid is also increasing the dependence of local authorities on international assistance. It will take time and difficulty to weaken this dependence which is exacerbating more failure in conservation in the island. Long-term 
solutions to deal with root causes of the system need to be implemented to avoid the unintended consequences from the easy fix.

Generally, dealing effectively with shifting the burden structures requires an integrated approach that strengthens the fundamental response in the balancing loop (B7), and weakens the symptomatic response in the reinforcing loop (R14). Strengthening management capacity is necessary not only for law enforcement forces to control effectively the wildlife poaching and trading in the island, but also decision makers because this underpins the success for conservation.

\section{CONCLUSIONS}

Using a systems perspective, the research investigated that the langur conservation is the dynamically complex system, linking seemingly disparate biological and cultural components, and requiring an understanding of the system as a whole. Rural poverty, low livelihoods options, human population growth, inappropriate tourism planning, and weak management capacity of local authorities are challenges that have prevented the langur population from increasing over the last twelve years.

Analyzing the dynamically complex system also found that there are more reinforcing loops than balancing loops in the whole system (Figure 2), and two systems archetypes of tragedy of the commons (Figure 3 and 4). This implies that negative effects from these interconnected components for the conservation status of the species could be worse over time. These negative effects are derived from practices that people are often inclined to make decisions and solutions to satisfy their wants. Everyone wants to maximize benefits from common resources but the resources are limited, leading to the degradation in langur populations and their habitats.

The systemic thinking provided innovative means to analyze and explore the dynamically complex wildlife conservation system, avoiding the unintended consequences emerging from the traditional methods. The linear thinking in biodiversity conservation has a narrow focus on characterizing the attributes of observable patterns but affording less attention to processes in the dynamically complex system. More specifically, conservation efforts mainly concentrates on protection of species or biodiversity but ignores cultural values of 
local people who have a long history of living and using natural resources in these areas. Consequently, forest protection laws are defied and forests resources are depleted. The dependence of local authorities on the international projects is an additional result of the linear thinking in biodiversity conservation.

A shift towards the systems perspective of viewing wildlife conservation as the dynamically complex system enables decision-makers to find sustainable solutions for both wildlife and people. This shift provides innovative ways through analyzing the CLD and systems archetypes to identify effective leverage points in the wildlife conservation system for systemic conservation strategies. An integrated implication for the conservation of the langurs is needed to save this species from extinction. Improving livelihoods for local people, and building capacity for local managers are the most important and sustainable interventions to last the effective conservation outcomes in the Cat Ba Island.

The outcomes from this research will be necessary for local managers to apply for successful conservation of the langurs and their habitats in the Cat Ba Island. The implementation of these solutions would help to strengthen the management capacity for local managers (shifting the burden systems archetype), and reduce the degradation of langurs and their habitats (tragedy of the common systems archetype). It is also important to note that it requires further investigations on interactions between ecological species and human diversity, and their interactive processes over time. More specifically, it is necessary to understand the effects of langur conservation on local residents, and cultural values, and returns in the island. This could help managers to identify and apply interactive applications of sustainable interventions for both wildlife and human in the long run.

\section{ACKNOWLEDGEMENTS}

This study was funded by an Alumni Small Grant of the Australian Scholarship for Development in Vietnam (ASDiV) Program. Our special thanks go to Cat Ba National Park and $\mathrm{Cat} \mathrm{Ba}$ Langur Conservation Project for making this research possible. 


\section{REFERENCES}

Bearer SM, Linderman J, Huang L, An G, He, Liu J. 2008. Effects of fuelwood collection and timber harvesting on giant panda habitat use. Biological Conservation 141: 385393.

Bleisch B, Le Xuan Canh, Covert HH, Long Yongcheng. 2008. Trachypithecus poliocephalus ssp. In: IUCN 2013. IUCN Red List of Threatened Species. Version 2013.2.<www.iucnredlist.org>. Accessed 18 March 2014.

Bosch O, Maani KE, Smith C. 2007. System thinking - Language of complexity for scientists and managers, paper presented to Improving the Triple Bottom Line Returns from Small-scale Forestry Ormoc, the Philippines, 18 - 21 June.

Brooks A. 2006. Improving effectiveness of conservation projects in Cat Ba Island Evaluating 10 years of international conservation aids, Vietnam IUCN Office, Hanoi, Vietnam.

Carter N H, Viña A, Hull V, McConnell WJ, Axinn W, Ghimire D, Liu J. 2014. Coupled human and natural systems approach to wildlife research and conservation. Ecology and Society 19: 43

Cavana RY, Davies PK, Robson RM, Wilson KJ. 1999. Drivers of quality in health services: Different worldviews of clinicians and policy managers revealed. System Dynamics Review 15: 331-340.

Dawkins Z. 2007. The Social impact of People-Oriented Conservation on Cat Ba Island, Viet Nam. Canberra: Australian National University, Research School of Pacific and Asian Studies, Resource Management in Asia-Pacific Program (Working Paper 68).

Elias AA. 2008. Towards a shared systems model of stakeholders in environmental conflict. International Transactions in Operational Research 15: 239-253.

Hoekstra J M, Boucher TM, Ricketts T H, Roberts C. 2005. Confronting a biome crisis: global disparities of habitat loss and protection. Ecology Letters 8: 23-29.

Kelly RA, Jakeman AJ, Barreteau O, Borsuk ME, Sawah S, Hamilton SH, Voinov AA. 2013. Selecting among five common modelling approaches for integrated environmental assessment and management. Environmental Modelling \& Software, 47: 159-181. 
Maani KE, Cavana RY. 2007. Systems Thinking, System Dynamic: Managing Change and Complexity, 2 edn, Prentice Hall, Auckland.

Manfredo MJ, Vaske JJ, Brown PJ, Decker DJ, Duke EA, (eds). 2009. Wildlife and society: the science of human dimensions. Island Press, Washington, D.C., US

Nadler T, Ha Thang Long. 2000. The Cat Ba langur: Past, Present and Future. The Definitive Report on Trachypithecus poliocephalus, the World's Rarest Primate. Report of the Frankfurt Zoological Society, Hanoi.

Nadler T, Momberg F, Dang NX, Lormee N. 2003. Vietnam primate conservation status review 2002. Part 2: Leaf monkeys. Hanoi: Fauna and Flora International - Vietnam Program and Frankfurt Zoological Society.

Nguyen Phien Ngung. 1997. Behavioral ecology and conservation status of Golden Headed Langur (Trachypithecus poliocephalus) in Cat Ba Island, Hai Phong, Vietnam. A Master thesis submitted to the Vietnam Forestry University.

Passaro RJ, Schrudde D, Stenke R, Phan Duy Thuc, Raffel M. 2014. Golden-headed Langur or Cat Ba Langur, Trachypithecus poliocephalus (Trouessart, 1911). In: C. Schwitzer RA, Mittermeier AB, Rylands LA, Taylor F, Chiozza EA, Williamson J, Wallis, Clark FE (eds.), Primates in Peril: The World's 25 Most Endangered Primates 2012-2014, pp. 59-60. IUCN SSC Primate Specialist Group (PSG), International Primatological Society (IPS), Conservation International (CI), and Bristol Zoological Society, Arlington, VA.

Phan DT, Baxter G, Smith C, Dao NH. 2014. Population status of the Southwest China Serow Capricornis milneedwardsii: A case study in Cat Ba Archipelago, Vietnam. Pacific Conservation Biology 20: 385-391.

Quatro SA, Waldman DA, Galvin BM. 2007. Developing holistic leaders: Four domains for leadership development and practice. Human Resource Management Review 17: 427441.

Rindfuss RRB, Entwisle SJ, Walsh L, An N, Badenoch DG, Brown P, Deadman TP, Evans, Fox J, Geoghegan M, Gutmann M, Kelly M, Linderman J, Liu GP, Malanson CF, Mena JP, Messina EF, Moran DC, Parker W, Parton P, Prasartkul DT, Robinson Y, Sawangdee LK, Vanwey, Verburg PH. 2008. Land use change: complexity and comparisons. Journal of Land Use Science 3:1-10. 
Schneider I, Tien I, Rode J, Levelink P, Schrudde D. 2010. Behavioral observations and notes on the vertical ranging pattern of the critically endangered $\mathrm{Cat} \mathrm{Ba}$ langur (Trachypithecus poliocephalus poliocephalus) in Vietnam. Primate Conservation 25: $111-117$

Senge PM. 2006. The Fifth Discipline; the Art and Practice of the Learning Organization. Doubleday: New York, London, Toronto, Sydney, Auckland.

Stenke R. 2001. Unpublished ZSCSP - report to Conservation International.

Stenke R, Chu Xuan Canh. 2004. The golden-headed langur (Trachypithecus poliocephalus poliocephalus) on Cat $\mathrm{Ba}$ Island-status, threat factors, and recovery options. In: Conservation of Primates in Vietnam, T. Nadler, U. Streicher and Ha Thang Long (eds.), pp.72 - 77. Frankfurt Zoological Society, Hanoi.

Sterling EJ, Gómez A, Porzecanski AL. 2010. A systemic view of biodiversity and its conservation: Processes, interrelationships, and human culture. BioEssays 32: 10901098.

Sterman JD. 2000. Business Dynamics: System Thinking and Modelling for a Complex World. Irwin McGraw-Hill: New York. 